\title{
Ultrasonographic evaluation of com- mon compression neuropathies in the upper limb
}

Jung Im Seok

Department of Neurology, Catholic University of Daegu School of Medicine, Daegu, Korea

Received: November 16, 2019

Revised: February 10, 2020

Accepted: February 11, 2020

\section{Correspondence to}

Jung Im Seok

Department of Neurology, Catholic University of Daegu School of Medicine, 33 Duryugongwon-ro 17-gil, Nam-gu, Daegu 42472, Korea

Tel: $+82-53-650-3440$

Fax: +82-53-654-9786

E-mail:ji-helpgod@hanmail.net

ORCID

Jung Im Seok

https://orcid.org/0000-0001-9219-9093
Neuromuscular ultrasonography has emerged over the last decade as a useful tool for diagnosing peripheral nerve disorders. It has been studied extensively with a particular focus on the assessment of compression neuropathies. Neuromuscular ultrasonography complements electrodiagnostic studies well by visualizing both the nerve anatomy and surrounding structures, providing useful data that cannot be obtained using the latter methodology only. This review article summarizes and synthesizes the literature focusing on the diagnostic role of neuromuscular ultrasonography in common compression neuropathies of the upper limb.

Key words: Nerve compression syndromes; Ultrasonography; Upper extremity

\section{INTRODUCTION}

Compression neuropathy is a common disorder of peripheral nerves caused by mechanical compression whose clinical manifestations include pain, paresthesia, numbness, and muscle weakness resulting from a loss of function (motor and/or sensory) of the affected nerve. The term entrapment neuropathy is sometimes used interchangeably with compression neuropathy, but it describes only a subset of compression neuropathies resulting from chronic compression between the ligamentous canal and adjacent bony surfaces. Compression neuropathies of the upper limb are common in the general population, including carpal tunnel syndrome (CTS), ulnar neuropathy at the elbow (UNE), and radial neuropathy at the spiral groove (SG).

Compression neuropathy is often diagnosed clinically and confirmed by electrodiagnosis (EDX). Although this method is the first line of diagnosis, it has two key limitations: the inability to provide anatomic data and discomfort for the patient. In contrast, neuromuscular ultrasonography is painless, and it also complements EDX well by being able to detect a structural cause of the compression and focal nerve swelling.

\section{Copyright $\odot 2020$ The Korean Society of Clinical Neurophysiology}

This is an Open Access article distributed under the terms of the Creative Commons Attribution Non-Commercial License (http:// creativecommons.org/licenses/by-nc/4.0) which permits unrestricted non-commercial use, distribution, and reproduction in any medium, provided the original work is properly cited. 


\section{COMMON SONOGRAPHIC FINDINGS ASSOCIATED WITH COMPRESSION NEU- ROPATHY}

Abnormal sonographic findings associated with compression neuropathy include enlargement of the nerve proximal to the site of compression, decreased echogenicity, and increased vascularity. Increased nerve cross-sectional area (CSA) has been the most reliable parameter for diagnosing compression neuropathy, mainly due to it providing quantitative and easily measurable data. We have previously published normal reference values for CSA in the Korean population (Table 1), as well as cutoff values for diagnosing neuropathy of $12.7 \mathrm{~mm}^{2}$ for the median nerve at the carpal tunnel and $8.9 \mathrm{~mm}^{2}$ for the ulnar nerve at the medial epicondyle. ${ }^{1}$
A new sonographic parameter for diagnosing compressive neuropathy is the ultrasonographic Tinel sign. ${ }^{2}$ In a physical examination, a positive Tinel sign is when the palpation of injured nerves causes a tingling sensation, and is commonly observed in patients with CTS. The ultrasonographic Tinel sign produces paresthesias when the ultrasound probe compresses an enlarged focal nerve lesion, which can be helpful in diagnosing compressive neuropathy.

\section{MEDIAN NEUROPATHY AT THE WRIST}

\section{Diagnosis}

CTS is the most common type of nerve compression encountered in clinical practice, and EDX has traditionally been used as the gold standard for diagnosing this syndrome.

Table 1. Normal reference values for $\mathrm{CSA}^{1}$

\begin{tabular}{lcccc} 
Nerve & Site & Mean \pm SD & Percentiles (2.5th, 97.5th) $^{\text {Reference range }^{\mathbf{a}}}$ \\
\hline Median & Carpal tunnel & $9.58 \pm 1.55$ & $7.02,12.58$ & $6.48-12.68$ \\
Median & Forearm & $6.87 \pm 1.61$ & $4.91,10.19$ & $4.91-10.09$ \\
Ulnar & Wrist & $4.72 \pm 0.91$ & $3.21,6.10$ & $2.90-6.54$ \\
Ulnar & Medial epicondyle & $6.64 \pm 1.33$ & $4.81,8.89$ & $4.81-8.89$ \\
Radial & Spiral groove & $6.48 \pm 1.68$ & $4.22,9.97$ & $4.22-9.97$ \\
\hline
\end{tabular}

All values are in $\mathrm{mm}^{2}$

CSA, cross-sectional area; SD, standard deviation.

The reference range was determined as the mean $\pm 2 \times$ SD for normally distributed data and between the 2.5th and 97.5th percentiles for nonnormally distributed data.
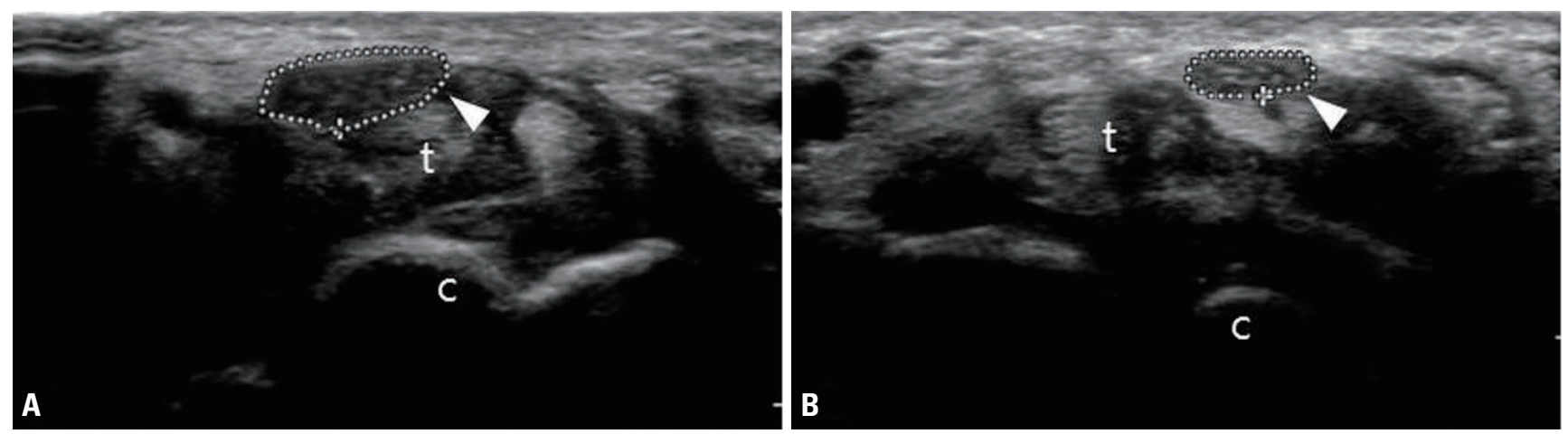

Fig. 1. Transverse view of the median nerve at the carpal tunnel of a 51-year-old woman who presented with left-hand paresthesia and muscle wasting of the thenar eminence. (A) Transverse view of the left median nerve (arrowhead) at the carpal tunnel showing an enlarged and hypoechoic nerve (cross-sectional area [CSA] of the nerve was $24.6 \mathrm{~mm}^{2}$ ). (B) The right median nerve (arrowhead) in the same location had a CSA of 10.6 mm². $t$, flexor tendons; c, carpal bones. 
Several studies have compared the diagnostic capabilities of sonography and EDX, and their inconsistent results suggest that neither EDX nor ultrasonography is diagnostically superior. ${ }^{3-5}$ Increased CSA of the median nerve proximal to the carpal tunnel is the most common finding in CTS (Fig. 1). The American Academy of Neurology criteria indicate that ultrasound measurement of the CSA of the median nerve at the wrist has a Level A recommendation for diagnosing CTS. ${ }^{6}$ Recent studies have demonstrated that measuring the median nerve at the carpal tunnel outlet improves the reliability of CTS diagnoses, because isolated enlargement of the median nerve in the distal carpal tunnel or palm instead of the wrist has been identified in some CTS patients. ${ }^{7.8}$

While CSA is the main parameter for diagnosing CTS, assessing the mobility and echo intensity of the median nerve and performing blood flow imaging can also be beneficial. The mean grade of median nerve mobility was found to be significantly reduced in patients with CTS. ${ }^{9}$ The degree of intraneural vascularity is strongly correlated with the severity of CTS, and so adding intraneural vascularity improves the diagnostic sensitivity. ${ }^{10}$

\section{Additional value}

Ultrasound imaging also provides several other types of useful information in addition to simply diagnosing CTS. First, ultrasonography may be complementary in classifying the CTS severity. Previous studies have observed significant correlations between the CSA and conventional measures of CTS severity, including clinical scales and neurophysiological classification. ${ }^{11,12}$
Second, ultrasonography can detect underlying structural causes of CTS that are not evident in EDX. Although most forms of CTS are idiopathic or associated with systemic diseases, some are caused by space-occupying lesions or structural abnormalities. Idiopathic CTS is generally known to occur bilaterally and insidiously. One study found that 10 out of 11 patients with space-occupying lesions had unilateral CTS. ${ }^{13}$ Acute CTS can be associated with hemorrhage or thrombosis of a persistent median artery. ${ }^{14}$ Therefore, screening for structural abnormalities as potential causes of CTS is necessary in affected individuals with atypical symptoms such as purely unilateral or abrupt onset. ${ }^{15}$

Third, ultrasonography can help to identify anatomic variants such as bifid median nerve and persistent median artery (Fig. 2), which we have previously reported to be present in $7.5 \%$ and $2.5 \%$, respectively, of the Korean population. ${ }^{1}$ Dilated or thrombosed persistent median arteries are known to cause CTS. Preoperative knowledge of these variants may be crucial in determining the best surgical approach and preventing potential complications. A particularly notable recent finding is the ability to identify Martin-Gruber anastomosis using ultrasonography. ${ }^{16}$

Fourth, ultrasonography can be used for follow-up examinations after treatment. Several studies have shown a significant decrease in the CSA of an enlarged nerve following local steroid injection or carpal tunnel release. ${ }^{17,18}$ A particularly important application is using postoperative ultrasonography to identify the causes of treatment failure in patients who do not improve. ${ }^{19}$
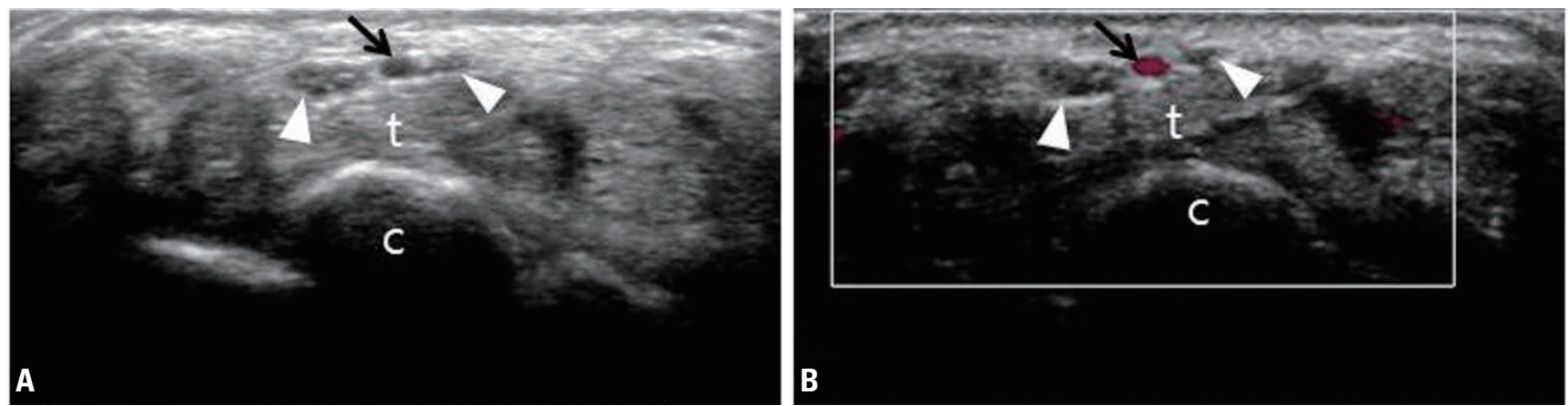

Fig. 2. Ultrasonography (A) and color Doppler sonography (B) revealing a bifid median nerve (white arrowheads) and persistent median artery (black arrows) of the wrist. t, flexor tendons; c, carpal bones. 

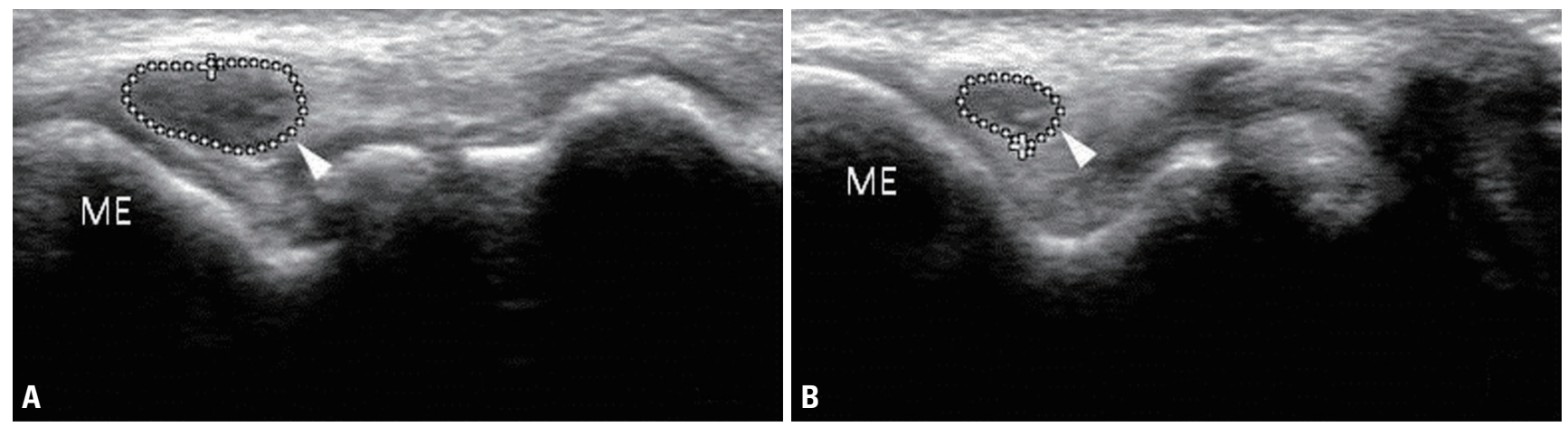

Fig. 3. Transverse view of the ulnar nerve at the medial epicondyle. A 66-year-old man developed paresthesia and numbness of the left hand (ulnar side) at 1 week after macular hole surgery. Face-down positioning was recommended to achieve macular hole closure. The patient placed pressure directly on his bent elbow to maintain the face-down positioning. (A) Transverse view of the left ulnar nerve (white arrowhead) showing an enlarged and hypoechoic nerve (cross-sectional area [CSA] of the nerve was $20.4 \mathrm{~mm}^{2}$ ). (B) The right ulnar nerve in the same location had a CSA of $7.8 \mathrm{~mm}{ }^{2}$. ME, medial epicondyle. Reproduced from Bae and Seok Ann Clin Neurophysiol 2014;16:92-94, with permission of The Korean Society of Clinical Neurophysiology. 22
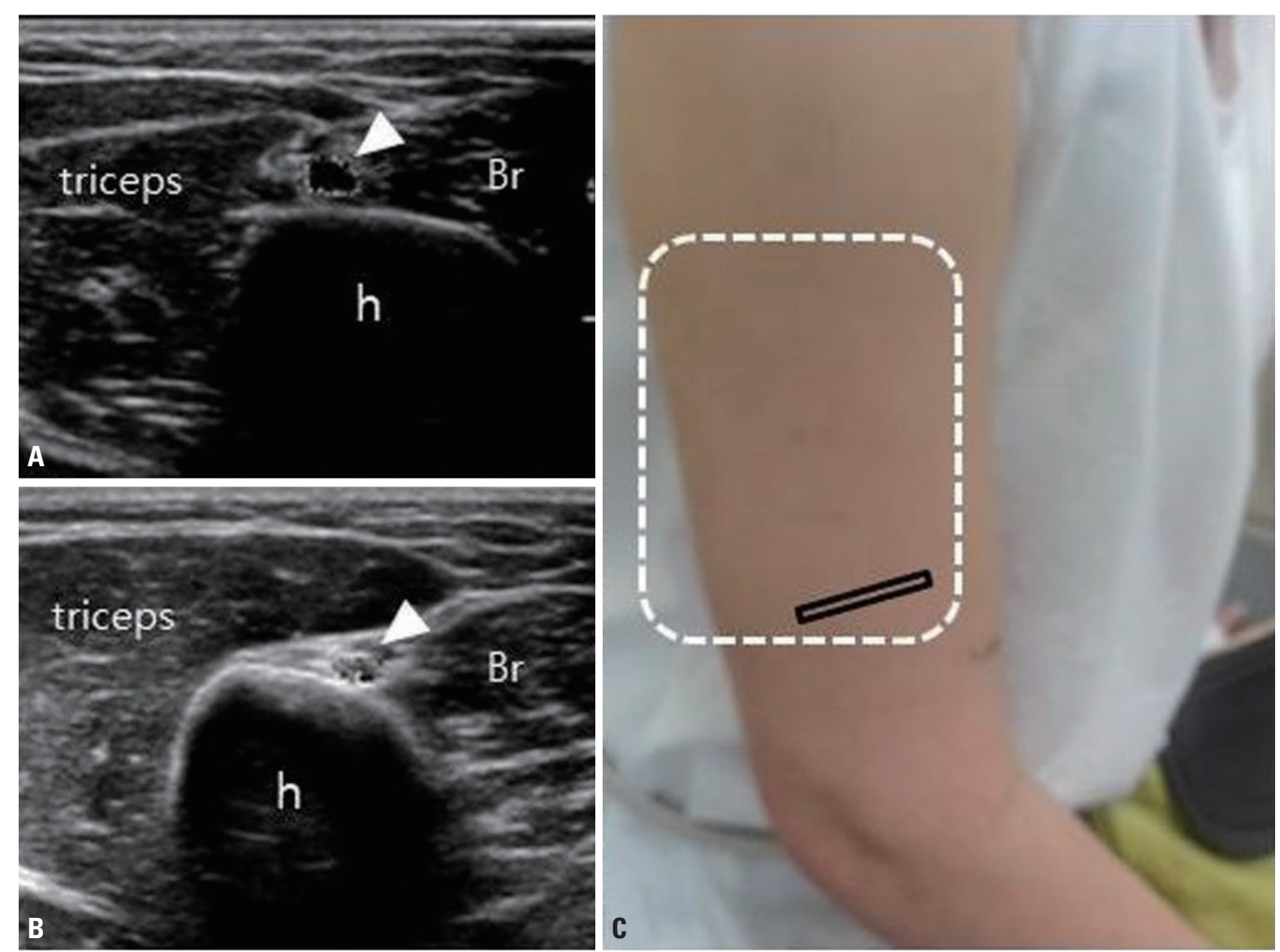

Fig. 4. Transverse view of the radial nerve at the spiral groove of a 33-year-old woman who presented with wrist drop of the right arm. She had undergone cryolipolysis on both upper arms immediately prior to the onset of symptoms. Cryolipolysis can damage nerves due to compression and/ or hypothermia that occurs during the procedure. (A) The cross-sectional area of the nerve (white arrowheads) at the level of the spiral groove had increased to $8.2 \mathrm{~mm}^{2}$. (B) The left radial nerve in the same location exhibited normal echogenicity and size $\left(4 \mathrm{~mm}^{2}\right)$. (C) The white dotted line indicates the attachment site of the cooling plate. h, humerus; Br, brachialis. Adapted from Baek et al. J Korean Neurol Assoc 2017;35:30-32, with permission of Korean Neurological Association. ${ }^{35}$ 


\section{ULNAR NEUROPATHY AT THE ELBOW}

\section{Diagnosis}

Nerve conduction studies (NCS) are less sensitive for diagnosing UNE than CTS. This reduced sensitivity may be due to subluxation or dislocation of the ulnar nerve over the medial epicondyle upon elbow flexion, resulting in inaccurate measurements of the nerve length. Overestimating the true length of the ulnar nerve may lead to false-negative results. ${ }^{20,21}$ Increased CSA of the ulnar nerve segment around the elbow is the most common observation associated with UNE (Fig. 3). ${ }^{22}$ Notably, reference values for the CSA of the ulnar nerve at the elbow have been consistent across multiple studies, at 8-10 $\mathrm{mm}^{21,23,24}$ The sensitivity of an increased CSA or diameter of the ulnar nerve at the elbow is more than $80 \%$ in UNE. ${ }^{25}$ Because studies have used EDX as the reference standard when determining the sensitivity and specificity of ultrasonography in diagnosing UNE, it is difficult to determine which test has better diagnostic accuracy. However, ultrasonography is particularly useful in localizing the lesion in axonal UNE, which often cannot be localized in NCS. ${ }^{26,27}$ Furthermore, ultrasonography is helpful in identifying the site of compression in patients with suspected UNE who present with normal NCS findings. ${ }^{28}$

\section{Additional value}

Similarly to CTS, ultrasonography can provide several other types of useful information about UNE. First, the CSA of a nerve is significantly correlated with the severity grade obtained using EDX. ${ }^{29,30}$ Second, the ulnar nerve at the elbow can be displaced across the medial epicondyle during elbow flexion. This type of nerve movement, which is not uncommon in healthy controls, can be easily detected in real time using ultrasonography. ${ }^{25}$ It has been suggested that an ulnar nerve exhibiting subluxation and dislocation is at a higher risk of UNE. Recent reports have proposed that subluxation can be a risk factor for developing compressive neuropathy, whereas dislocation appears to be protective against compression. ${ }^{31}$ However, the relationship between ulnar nerve movement and UNE remains to be confirmed. ${ }^{32}$

In addition, ultrasonography is effective for detecting underlying abnormalities that may be associated with UNE. Static and real-time ultrasonography can be used to assess snapping of the medial head of the triceps ${ }^{33}$ and anconeus epitrochlearis muscle that can predispose to UNE. ${ }^{34}$

\section{RADIAL NEUROPATHY AT THE SG}

Compression neuropathies of the radial nerve are common and widely recognized in the region of the SG. Radial neuropathy at the SG is also known as the "Saturday night palsy" that results from direct pressure against a firm object that often occurs during alcohol intoxication. The radial nerve lies close to the humerus in the SG, making it susceptible to mechanical compression. Ultrasonography appears to be a sensitive and specific method for revealing radial nerve enlargement at the SG (Fig. 4). ${ }^{35,36}$ Although normal reference values have previously been reported for the radial nerve in the SG, these are based on only a few studies and are variable compared to those for the median and ulnar nerves. ${ }^{36-38}$ Therefore, comparisons with reference values for the contralateral side is often helpful in suspected cases of unilateral radial neuropathy at the SG.

\section{CONCLUSIONS}

Ultrasonography is useful for the diagnosis of compression neuropathies. It can provide diagnostic confirmation of compressive neuropathy and also makes it possible to exactly locate the compression site. Ultrasonography also provides information about dynamic movements of the nerves or surrounding muscles that may be helpful in understanding the underlying pathophysiology of nerve compression. Finally, this technique can be used to identify anatomic lesions that can cause nerve compression, such as ganglia, hematomas, or tumors.

\section{Conflicts of Interest}

The authors declare no conflicts of interest relevant to this article.

\section{REFERENCES}

1. Seok Jl, Lee SB, Bae CB. Ultrasonographic findings of the normal nerves in common entrapment site; cross-sectional area refer- 
ence value and normal variant. J Korean Neurol Assoc 2015;33:812.

2. Yalcin E, Unlu E, Onder B, Akyuz M. Ultrasonographic Tinel sign: two case reports. Acta Reumatol Port 2015;40:299-301.

3. Fowler JR, Munsch M, Tosti R, Hagberg WC, Imbriglia JE. Comparison of ultrasound and electrodiagnostic testing for diagnosis of carpal tunnel syndrome: study using a validated clinical tool as the reference standard. J Bone Joint Surg Am 2014;96:e148.

4. Kwon BC, Jung Kl, Baek GH. Comparison of sonography and electrodiagnostic testing in the diagnosis of carpal tunnel syndrome. J Hand Surg Am 2008;33:65-71.

5. Pastare D, Therimadasamy AK, Lee E, Wilder-Smith EP. Sonography versus nerve conduction studies in patients referred with a clinical diagnosis of carpal tunnel syndrome. J Clin Ultrasound 2009:37:389-393.

6. Cartwright MS, Hobson-Webb LD, Boon AJ, Alter KE, Hunt CH, Flores VH, et al. Evidence-based guideline: neuromuscular ultrasound for the diagnosis of carpal tunnel syndrome. Muscle Nerve 2012;46:287-293.

7. Paliwal PR, Therimadasamy AK, Chan YC, Wilder-Smith EP. Does measuring the median nerve at the carpal tunnel outlet improve ultrasound CTS diagnosis? J Neurol Sci 2014;339:47-51.

8. Csillik A, Bereczki D, Bora L, Arányi Z. The significance of ultrasonographic carpal tunnel outlet measurements in the diagnosis of carpal tunnel syndrome. Clin Neurophysiol 2016;127:35163523.

9. Park GY, Kwon DR, Seok JI, Park DS, Cho HK. Usefulness of ultrasound assessment of median nerve mobility in carpal tunnel syndrome. Acta Radiol 2018;59:1494-1499.

10. Karahan AY, Arslan S, Ordahan B, Bakdik S, Ekiz T. Superb microvascular imaging of the median nerve in carpal tunnel syndrome: an electrodiagnostic and ultrasonographic study. J Ultrasound Med 2018;37:2855-2861.

11. Azami A, Maleki N, Anari H, Iranparvar Alamdari M, Kalantarhormozi M, Tavosi Z. The diagnostic value of ultrasound compared with nerve conduction velocity in carpal tunnel syndrome. Int J Rheum Dis 2014;17:612-620.

12. Padua L, Pazzaglia C, Caliandro P, Granata G, Foschini M, Briani C, et al. Carpal tunnel syndrome: ultrasound, neurophysiology, clinical and patient-oriented assessment. Clin Neurophysiol 2008;119:2064-2069.

13. Kang HJ, Jung SH, Yoon HK, Hahn SB, Kim SJ. Carpal tunnel syndrome caused by space occupying lesions. Yonsei Med J 2009:50:257-261.
14. Akgun AS, Ertan G, Ulus S. Acute carpal tunnel syndrome caused by thrombosed persistent median artery associated with bifurcated median nerve in a pregnant woman. BMJ Case Rep 2017 Sep 19. [Epub]. DOI: 10.1136/bcr-2017-221446.

15. Nakamichi K, Tachibana S. Unilateral carpal tunnel syndrome and space-occupying lesions. J Hand Surg Br 1993;18:748-749.

16. Gans P, Van Alfen N. Nerve ultrasound showing Martin-Gruber anastomosis. Muscle Nerve 2017;56:E46-E47.

17. Cartwright MS, White DL, Demar S, Wiesler ER, Sarlikiotis T, Chloros GD, et al. Median nerve changes following steroid injection for carpal tunnel syndrome. Muscle Nerve 2011;44:25-29.

18. Smidt MH, Visser LH. Carpal tunnel syndrome: clinical and sonographic follow-up after surgery. Muscle Nerve 2008;38:987-991.

19. Tan TC, Yeo CJ, Smith EW. High definition ultrasound as diagnostic adjunct for incomplete carpal tunnel release. Hand Surg 2011;16:289-294.

20. Kim BJ, Koh SB, Park KW, Kim SJ, Yoon JS. Pearls \& Oy-sters: false positives in short-segment nerve conduction studies due to ulnar nerve dislocation. Neurology 2008;70:e9-e13.

21. Kim BJ, Date ES, Lee SH, Yoon JS, Hur SY, Kim SJ. Distance measure error induced by displacement of the ulnar nerve when the elbow is flexed. Arch Phys Med Rehabil 2005;86:809-812.

22. Bae CB, Seok Jl, Lee DK. Ulnar neuropathy as a complication of face-down positioning after macular hole surgery. Ann Clin Neurophysiol 2014;16:92-94.

23. Fink A, Teggeler M, Schmitz M, Janssen J, Pisters M. Reproducibility of ultrasonographic measurements of the ulnar nerve at the cubital tunnel. Ultrasound Med Biol 2017;43:439-444.

24. Terayama Y, Uchiyama S, Ueda K, Iwakura N, Ikegami S, Kato Y, et al. Optimal measurement level and ulnar nerve cross-sectional area cutoff threshold for identifying ulnar neuropathy at the elbow by MRI and ultrasonography. J Hand Surg Am 2018;43:529536.

25. Beekman R, Visser LH, Verhagen WI. Ultrasonography in ulnar neuropathy at the elbow: a critical review. Muscle Nerve 2011;43:627-635.

26. Pelosi L, Tse DMY, Mulroy E, Chancellor AM, Boland MR. Ulnar neuropathy with abnormal non-localizing electrophysiology: clinical, electrophysiological and ultrasound findings. Clin Neurophysiol 2018;129:2155-2161.

27. Omejec G, Žgur T, Podnar S. Diagnostic accuracy of ultrasonographic and nerve conduction studies in ulnar neuropathy at the elbow. Clin Neurophysiol 2015;126:1797-1804.

28. Yoon JS, Walker FO, Cartwright MS. Ulnar neuropathy with nor- 
mal electrodiagnosis and abnormal nerve ultrasound. Arch Phys Med Rehabil 2010;91:318-320.

29. Mondelli M, Filippou G, Frediani B, Aretini A. Ultrasonography in ulnar neuropathy at the elbow: relationships to clinical and electrophysiological findings. Neurophysiol Clin 2008;38:217-226.

30. Bayrak AO, Bayrak IK, Turker H, Elmali M, Nural MS. Ultrasonography in patients with ulnar neuropathy at the elbow: comparison of cross-sectional area and swelling ratio with electrophysiological severity. Muscle Nerve 2010;41:661-666.

31. Leis AA, Smith BE, Kosiorek HE, Omejec G, Podnar S. Complete dislocation of the ulnar nerve at the elbow: a protective effect against neuropathy? Muscle Nerve 2017;56:242-246.

32. Van Den Berg PJ, Pompe SM, Beekman R, Visser LH. Sonographic incidence of ulnar nerve (sub) luxation and its associated clinical and electrodiagnostic characteristics. Muscle Nerve 2013;47:849855.

33. Jacobson JA, Jebson PJ, Jeffers AW, Fessell DP, Hayes CW. Ulnar nerve dislocation and snapping triceps syndrome: diagnosis with dynamic sonography-report of three cases. Radiology 2001;220:601-605.

34. Lee SU, Kim MW, Kim JM. Ultrasound diagnosis of double crush syndrome of the ulnar nerve by the anconeus epitrochlearis and a ganglion. J Korean Neurosurg Soc 2016;59:75-77.

35. Baek JG, Park JA, Seok JI. Radial neuropathy after cryolipolysis. J Korean Neurol Assoc 2017;35:30-32.

36. Song S, Yoo Y, Won SJ, Park HJ, Rhee WI. Investigation of the diagnostic value of ultrasonography for radial neuropathy located at the spiral groove. Ann Rehabil Med 2018;42:601-608.

37. Won SJ, Kim BJ, Park KS, Yoon JS, Choi H. Reference values for nerve ultrasonography in the upper extremity. Muscle Nerve 2013;47:864-871.

38. Qrimli $M$, Ebadi $H$, Breiner $A$, Siddiqui $H$, Alabdali $M$, Abraham A, et al. Reference values for ultrasonograpy of peripheral nerves. Muscle Nerve 2016;53:538-544. 